This item was submitted to Loughborough's Research Repository by the author.

Items in Figshare are protected by copyright, with all rights reserved, unless otherwise indicated.

\title{
Income disparities of burglary risk: security availability during the crime drop
}

\section{PLEASE CITE THE PUBLISHED VERSION}

http://dx.doi.org/10.1093/bjc/azr010

\section{PUBLISHER}

Oxford University Press on behalf of the Centre for Crime and Justice Studies (ISTD) / @ The Authors

\section{VERSION}

AM (Accepted Manuscript)

\section{LICENCE}

CC BY-NC-ND 4.0

\section{REPOSITORY RECORD}

Tilley, Nick, Andromachi Tseloni, and Graham Farrell. 2019. "Income Disparities of Burglary Risk: Security Availability During the Crime Drop”. figshare. https://hdl.handle.net/2134/15161. 
This item was submitted to Loughborough's Institutional Repository (https://dspace.lboro.ac.uk/) by the author and is made available under the following Creative Commons Licence conditions.

\section{creative
commons}

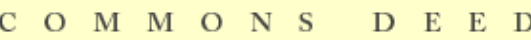

Attribution-NonCommercial-NoDerivs 2.5

You are free:

- to copy, distribute, display, and perform the work

Under the following conditions:

Attribution. You must attribute the work in the manner specified b the author or licensor.

Noncommercial. You may not use this work for commercial purposes.

No Derivative Works. You may not alter, transform, or build upon this work.

- For any reuse or distribution, you must make clear to others the license terms of this work.

- Any of these conditions can be waived if you get permission from the copyright holder.

Your fair use and other rights are in no way affected by the above.

This is a human-readable summary of the Leqal Code (the full license).

\section{Disclaimer 만}

For the full text of this licence, please go to: http://creativecommons.org/licenses/by-nc-nd/2.5/ 
Income - disparities of burglary risk and security availability over time

Income - disparities of burglary risk and security availability over time

\author{
Nick Tilley $^{1}$ \\ Andromachi Tseloni ${ }^{2,4}$ \\ Graham Farrell ${ }^{3}$
}

January 2011

${ }^{1}$ Jill Dando Institute of Crime Science, University College London.

E-mail: n.tilley@ucl.ac.uk

${ }^{2}$ Criminology, Public Health and Policy Studies, Nottingham Trent University, Burton street, Nottingham NG1 4BU. Tel. 0115 8482167, Fax . 0115 8486829, E-mail: andromachi.tseloni@ntu.ac.uk.

${ }^{3}$ Criminology, University of Loughborough.

E-mail: g.farrell@1boro.ac.uk.

${ }^{4}$ Corresponding author.

Word count: 7,215 including Abstract, References, Tables and Figures. 
Income - disparities of burglary risk and security availability over time

\begin{abstract}
In the past fifteen years volume crimes dropped substantially in most countries with reliable crime trend estimates. In England and Wales domestic burglary fell by $58 \%$ between 1995 and 2008/09, the trend levelling off after 2005/6. Wider use of more and better security arguably contributed to these drops. The availability of enhanced and especially basic security increased between 1997 and 2005/06, while burglary risk fell for all population income groups. Considering, however, the financial cost of burglary protection devices it is not surprising that enhanced security continues to be more accessible to better off households. In 2005/06 the most affluent households were $60 \%$ more likely to have such devices compared to the poorest. This is consistent with the finding that nationally burglary drops have occurred least amongst the poorest segments of population. The better off continue to benefit most in terms of crime protection: burglary risk differentials between the lowest and all other income groups widened during the decade up to 2005/06. Security Impact Assessment Tool analysis however shows that enhanced security confers greatest burglary protection for those who can least afforded it. These results suggest that making enhanced security available to the poorest would further reduce national burglary rates.
\end{abstract}


Income - disparities of burglary risk and security availability over time

\section{Introduction}

The past ten to fifteen years have seen a drop in high-volume crimes in most industrial societies (Tseloni et al. 2010). Improvements in security appear to have played a major part in producing these crime falls (Farrell et al. 2011). Research on patterns of displacement and diffusion of benefit finds that improvements in security do not generally result in a simple redistribution of the total volume of crime. The conclusions from systematic overviews of the displacement literature are unequivocal: one crime thwarted does not inevitably lead to another manifestation of criminal behaviour (Hesseling 1994; Guerette and Bowers 2009).

Nevertheless uneven access to crime-reducing security measures (and of other situational resources relating to crime opportunities) may have benefited those who are economically better off more than those who are poorer, and hence contributed to the observed uneven levels of crime across different communities. On the whole income and wealth have tended to grow, at least since the Second World War, in most industrial societies. Likewise, in those same societies, crime tended to increase, at least until the early to mid 1990s. In fact the changes in income and wealth and in crime levels are causally connected, according to routine activities theory (Cohen and Felson 1979). More goods provide more to steal. More mobility provides for more anonymity, fostering crime. Greater participation in the labour market, creating more wealth, also creates less domestic guardianship. More cars mean both more crime targets and more tools to help commit crimes.

At any given point in time there is, by definition, a fixed volume of crime or income, and we can look at its distribution. When coming to a judgement over policy and 
Income - disparities of burglary risk and security availability over time

practice, however, we need to consider changes over time both in the volume and the distribution of crime. This paper's focus is on crime as a distributive 'bad' and crime prevention, other things being equal ${ }^{1}$, as a distributive 'good'.

The conception of distributive justice used in this paper draws on the work of John Rawls. Rawls was concerned with the 'distribution of social and economic advantages' (1971: 61). It is these as they relate specifically to trends in crime and to crime prevention that are focused on here. It is proposed that the rank order of preferred trends shown in Table 1 is that which would be agreed by self-interested actors operating under Rawls' 'veil of ignorance'. Here no-one knows in advance where they will stand in the social order or what capacities they have. Most would almost certainly conclude that declining crime for all associated with declining relativities between groups is, all other things being equal, the most desirable development. There is also likely to be a consensus that increasing crime rates for all groups with increasing relativities between groups are, all other things being equal, the least desirable development. The rank order of the intermediary patterns is less certain. The most problematic part of the ranking in Table 1 is that between (4) and (5). Some social democrats might put (5) before (4): they would prefer a decrease in crime relativities even if the overall level of crime increases rather than an overall reduction in the level of crime where the higher crime groups come to suffer more crime and hence relativities increase. For the purposes of this paper, however, such nuances need not bother us: the actual trends examined fit neither of these possibilities as it will be seen in the final section of this study.

\footnotetext{
${ }^{1}$ This is not to say that all that is done in the name of crime prevention is always an unequivocal good. All strategies embody more or less contentions moral assumptions and unintended consequences follow, which can be undesirable (see Tilley 2009).
} 
Income - disparities of burglary risk and security availability over time

$<$ Table 1 about here $>$

One way in which risks of crime can be reduced is through the use of security devices and security devices clearly cost money. Those at risk of crime are unevenly able to protect themselves through enhanced security because of the different level of resources available to them. Even if displacement from the better to worse protected does not occur, the consequence may still be increases in crime risk inequalities as some can better afford to reduce their risks than others.

This paper examines domestic burglary in England and Wales to explore what the available evidence suggests about security and changes in distributive justice as ranked in Table 1. Domestic burglary is chosen because all households are vulnerable to it and its harms are high and well-known. In addition to incurring material losses those burgled often experience feelings of violation and insecurity (Maguire 1982). Moreover, domestic burglary is clearly open to efforts at prevention involving improvements in security (Forrester et al. 1990). England and Wales is focused on because the British Crime Survey, conducted since 1981, provides a rich data source on domestic burglary and the use of security devices.

The research questions of this study are the following:

o Are there any income-related differentials in burglary risk and security availability?

o If so how have they progressed during (a part of) the recent period of considerable and sustained crime drops?

o Are security differentials associated with any burglary disparities? 
Income - disparities of burglary risk and security availability over time

The recently suggested in the literature Security Impact Assessment Tool (Farrell et al. 2011), which measures the level of protection conferred by different security devices $^{2}$ is employed here in a novel way, i.e., across income groups (rather than the entire population) and over time.

The next section describes the data and thereafter the analyses results, first with regards to each variable of interest, i.e. security and burglary, and then in combination, are presented. A discussion section concludes the paper, which includes suggestions for alternative security and situational crime prevention strategies to reduce overall levels of burglary in a manner that will also eliminate crime inequalities.

\section{Description of Data}

The analysis employs various sweeps of the British Crime Survey (BCS) between 1996 and 2005/06. The BCS has been administered by the Home Office since 1982, first, on a biennial basis and since 2001/02 with continuous annual sampling. Its reference period is the calendar year prior to the year of the fieldwork. For instance, the 1996 BCS measured crime in 1995. It is a large-scale survey of adults (16 years or older) living in private accommodation in England and Wales with currently over 40,000 respondents. In addition to measuring personal and household crimes and the

\footnotetext{
${ }^{2}$ The Security Impact Assessment Tool is a simple technique to assess the level of protection conferred by different security devices, whereby the odd ratio of victimisation without security is divided by the respective odd ratios of victimisation given a or a mixture of relevant security devises. The end result is the Security Protection Factor (SPF) which equals by definition 1, its minimum value, for targets without security. It enables researchers to quantify and rank the extent of protection conferred by different devices. Although odd ratios are routinely used to gauge the importance of individual victimisation risk factors, especially from logistic regression analysis (Walker et al. 2009), the SPF was first devised by Farrell et al. (2011) to assess the effectiveness of car security configurations. It allows direct comparisons across various individual and configurations of security devices drawn from respective bivariate analyses that can be performed by researchers without advanced statistical expertise.
} 
Income - disparities of burglary risk and security availability over time

circumstances under which they occurred, the BCS collects information on attitudes and beliefs on crime, offenders and the criminal justice system, routine activities and crime prevention as well as socio-economic and demographic characteristics of the respondents and their households. For detailed information please see the Technical Reports of its various sweeps which are publicly available at the UK Data Archive (UKDA, http://www.data-archive.ac.uk/).

For the purposes of this study information on household income from the Demographic questions section was merged with Follow-up information on security of home ${ }^{3}$ (Follow-up A for the 1998 BCS and Follow-up module C on Crime Prevention and Security for the 2005/06 sweep) and the flattened Victim Form data on burglary incidents per burglary victim. Although all burglary categories, i.e., total burglaries and their constituents, attempts and burglary with entry, have been analysed the later results section for brevity discusses the latter. This is because burglary with entry is the most serious type and usually involves both material loss and damage to the property from breaking and entering. Results relating to all burglaries and attempts are available from the authors.

Different security features may be reported for households burgled more than once during the reference period, each referring to a different incident. This is not unexpected as an initial burglary may prompt the victims to install additional security devices to avoid repetition or some devices may be damaged during the course of the first event. It however leads to multiple security characterisation of the household

\footnotetext{
${ }^{3}$ The 1998 Follow-up A was completed by a randomly selected half of the total respective sample. The 2005/06 Follow-up module C was given to a randomly selected quarter of the respective BCS sweep sample. Since later comparisons are made within each sweep this difference does not impact our analysis.
} 
Income - disparities of burglary risk and security availability over time

since the basis of this analysis is the household not the criminal incident. To overcome this problem we employed security information with respect to the first burglary the household experienced and disregarded the rest which may be thought as a result of that experience. In practice there were no more than fifteen (in the 1996 BCS) such cases in any one sweep (respective 7 and 4 in the 1998 and 2005/06 sweeps which are mostly used here for reasons outlined further down).

Households which moved house during the reference period contributed to the analysis as the victim's security information relates to the house which had been burgled irrespective of whether it was the one in which the victims resided at the time of the interview. In addition in only 2 cases of the aforementioned multiple security characterisation had the respective households moved house in 1997 and 2005/06. The analysis does not use the BCS weights: the incident one is irrelevant as we will examine burglary risk and the household weight does not essentially alter the results.

A potentially serious caveat is that this analysis underestimates burglary risks because the BCS completes up to six Victim Forms and collects detailed incident information for up to three crimes per respondent due to interview time constraints. This implies that only a portion of the crime experiences of the most vulnerable population features in crime statistics, albeit the most serious ones. Indeed according to standard BCS offence classification personal crimes have priority over household crimes which in turn come before vehicle crimes (Hales et al. 2000: 26 and Appendix G). Therefore it is possible that this study does not count burglaries of the homes of people with multiple personal crime experiences. It also ignores burglaries that were reported in the fourth to sixth Victim Form because house security at the time that a burglary 
Income - disparities of burglary risk and security availability over time

occurred was recorded only in the first three Victim Forms per respondent. Therefore $21.33 \%, 23.85 \%, 24.25 \%, 20.83 \%, 20.94 \%$ and $18.21 \%$ of 'known' burglaries in the 1996, 1998, 2000, 2001/02, 2003/04 and 2005/6 BCS, respectively, have not been examined due to lack of security information and this is likely to be biased towards the most vulnerable households with members suffering a large number of multiple crimes.

The BCS respondents are asked whether their annual household income falls in any given group of the following list: ‘Up to $£ 4,999$ ’, ‘ $£ 5,000$ - $£ 9,999$ ’, ‘ $£ 10,000$ $£ 19,999$ ', ‘ $£ 20,000$ - $£ 29,999 ’$ ' ‘ $£ 30,000$ - $£ 49,999$ ’ and ' $£ 50,000$ or more’. The last income bracket was introduced in the 1998 BCS while since 2006/07 the first two categories have been merged into one, 'Up to $£ 9,999$ '. A considerable proportion of respondents who do not report their income (7.8\% and 22\% in the 1998 and 2005/06 sweeps, respectively) are ignored in this discussion for brevity although they have been included in the original analyses. Their home security and burglary ratings can be provided to interested readers upon request.

To keep the same income groups this study examines combined security and burglary changes that occurred between 1997 and 2005/06, i.e. it analyses the 1998 to 2005/06 sweeps. This bounding is expected to underestimate both burglary drops and security increases but mostly the latter. As burglary rates began to fall in 1995 whilst the trend levelled off after 2005/06 (Walker et al. 2009), the later analysis misses only the initial downfall. Changes in availability of security devices are, however, seriously underestimated by restricting the analysis period to 1997-2005/06 because steep 
Income - disparities of burglary risk and security availability over time

positive trends at least for some, i.e., light timers/ sensors, double or deadlocks and window locks, were observed from 1992 to 1997 (Tilley forthcoming).

Income differentials for the distribution of a number of societal 'goods' and 'bads', such as the security devices and burglary risks focused on this paper, are ideally examined via income deciles, i.e., contrasting the richest $10 \%$ of the population against the poorest $10 \%$. When income information is provided in brackets rather than via a single estimate, however, decile-based contrasts are not possible without interpolation and, considering the highly uneven distribution of both security devices and crime, interpolating their distribution within income brackets is not defensible.

Figure 1 shows the distribution of income in 1997 and 2005/06 based on BCS data. Evidently having the same income over time does not imply similar purchasing power and prosperity but a definite worsening due to inflation, which occurred at around $2.5 \%$ per annum over this period. Figure 1 offers, however, an indication of the relative income distribution conferred by the available groups. In 1997 the poorest $16 \%$ of the population in England and Wales earned up to $£ 4,999$ while by $2005 / 06$ that much was earned by the poorest $6 \%$ of the country. At the other extreme, households with annual incomes over $£ 49,999$ represented the richest $5 \%$ and $10 \%$ of the population in 1997 and 2005/06, respectively. Therefore in the forthcoming analysis these contrasts (the poorest $16 \%$ against the richest $5 \%$ in 1997 and the poorest $6 \%$ versus the richest $10 \%$ in $2005 / 06$ ) are implicit. The next two paragraphs give the profile of the lowest income groups, first by contrasting them to the rest of the population in England and Wales and then between them in order to gain a more holistic view of income disparities. 
Income - disparities of burglary risk and security availability over time

$<$ Figure 1 about here $>$

The two poorest segments of the population (i.e., with less than $£ 10,000$ ) differ to the rest with respect to all their BCS measured demographic and socio-economic attributes except ethnic group. They tend to live in households with fewer adults (1.4 compared to 2$)$, children ( 0.3 versus 0.6$)$ and cars ( 0.57 versus over 1.34$)$. Their household reference person (HRP) is on average over 55 years old (against 49 years old mean age for HRP of households with $£ 10,000$ or more), less likely to be in paid work (at least $18 \%$ against $71 \%$ ), more likely to look after family/home (9\% against $2 \%$ ) and to be classified as belonging to the (semi-) routine occupations (at least $20 \%$ against maximum $12 \%$ ) or those who have never worked (at least $4.8 \%$ against $1.2 \%$ ). They are more likely to be lone parent households (11.5\% versus maximum $4.6 \%)$ and to live in terraced (32.9\% against $27.3 \%$ ) socially rented accommodation (at least $39 \%$ versus $12 \%$ ). The respondent from low income households is female (at least $62 \%$ compared to $52 \%$ ), less likely to be married, cohabiting or divorced (at least $20 \%, 3 \%$ and $16 \%$ versus $54 \%, 10 \%$ and $8 \%$, respectively) and more likely to have a long-standing illness (at least 43\% versus $24 \%$ ).

Furthermore, households at below $£ 5,000$ per annum are unlike those in the next income group (£5,000-£9,999) with regards to: the HRP’s mean age $(54.7$ and 61.8, respectively) and his/her classification as inactive (never worked $8.5 \%$ and $4.8 \%$, respectively), long-term sick, retired or in full time education (respective 15.1\%, $37.4 \%$ and $4.4 \%$ for the lowest income group and $8.1 \%, 58.6 \%$ and $1.7 \%$ for the second lowest one); the respondent's non-white ethnic group (respective $9 \%$ and $5 \%$ which is the sample's average) and single, separated or widowed marital status 
Income - disparities of burglary risk and security availability over time (respective $31.4 \%, 5.4 \%$ and $22.4 \%$ for those below $£ 5,000$.against $20 \%, 3.8 \%$ and $31.6 \%$ for households at $£ 5,000-£ 9,999)$; household's home ownership (40.6\% and $51 \%$, respectively) or private renting ( $15 \%$ and $10.1 \%$, respectively) and living in purpose built flat $(20.6 \%$ and $14.9 \%$, respectively). The figures in brackets correspond to the 2005/06 BCS sample for which one might reasonably expect that income differences are accentuated not least due to the further marginalisation of low income groups compared to 1997 (see Figure 1). The association of income with each aforementioned characteristic is highly statistically significant ( $p$-values $<0.001$ for corresponding F-tests and $\chi^{2}$ statistics). These results are available from the authors.

The BCS asks victims of burglary and respondents of the relevant follow-up module whether the house has any of the following ten security devices: burglar alarm, dummy alarm box, security chains, indoor lights on a timer or sensor switch, outdoor lights on a timer or sensor switch, bars or grills on windows, bars, a metal grill or a bar door, a dog (not in the 2005/06 BCS), double or deadlocks and window locks. Individual analysis of each device would have been impossible within each year due to low frequency for some of them. Table 2 shows the availability of burglary security devices in households in England and Wales in 1997 and 2005/06. We see that the most common devices are double deadlocks and window locks. The availability of all security devices increased over time except for security chains, bars or grills which were used by fewer households in 2005/06 than in 1997.

$<$ Table 2 about here $>$

To allow meaningful statistical comparisons here we employ the security devices classification which is used in Home Office burglary reports (see, for instance Flatley 
Income - disparities of burglary risk and security availability over time

et al. 2009), whereby availability of both double /deadlocks and window locks is considered basic security; any individual device or combinations of the remaining eight devices between them or with either double /deadlocks or window locks is classified as less than basic security; combinations of both double /deadlocks and window locks with any other device is enhanced security; and, finally, none is no security. This classification is not as arbitrary as it may seem at first glance: previous analyses of individual devices using various BCS sweeps have shown that the devices making up basic security are the two most effective ones in thwarting burglary, especially burglary with forced entry (Nicholas et al. 2005; Walker et al. 2009). The same reports suggest that burglar alarms and window bars /grills are not effective deterrents.

\section{Analysis}

\section{Security Differentials}

The current analyses compare enhanced and basic security against no or less than basic security ${ }^{4}$. Figures 2 and 3 present the distribution of these security combinations in 1997 and 2005/06, respectively, across the income groups which were introduced earlier and in Figure 1. Figure 4 shows their percentage change during the interim eight years. To facilitate comparisons the values are indexed to the poorest, whereby the proportion of households earning under $£ 5,000$ which reported each security combination equals 100 and that for any other income group is expressed relative to them. This can also be interpreted as the odds ratio of each security combination in any one income group compared to the lowest. For instance, households earning $£ 5,000-£ 9,999$ per annum were in $1997113 \%$ more likely to have more than basic

\footnotetext{
${ }^{4}$ Security devices analyses focus on the two end years of consistent BCS income measures, i.e., 1997 and 2005/06 because the multi-category nature of both income and security renders trend graphs of security by income cumbersome and ultimately unhelpful.
} 
Income - disparities of burglary risk and security availability over time

security than households at less than $£ 5,000$. The odds ratio of enhanced security for those at $£ 5,000$ - 99,999 is therefore 1.13 compared to the poorest. The association between security and income is statistically significant in both years $\left(\chi^{2}=232.02\right.$ and 148.02, respectively, at 12 degrees of freedom and $p$-values $\leq 0.000$ ).

$<$ Figures 2-4 about here $>$

In both years the highest proportion of households without at least basic security comes from the poorest population segment and this proportion falls as income rises so that the most affluent are over 50\% less likely to have none or less than basic security than the poorest (Figures 2 and 3). Over the period covered security differentials are maintained across income groups as the percentage of households without security or less than basic security fell for all income groups in a similar manner (Figure 4).

The availability of enhanced security, by contrast, increases with income and also in more pronounced manner than falls in households with no security or less than basic security availability falls. In 1997 households in the highest income group of $£ 50,000+$ were $80 \%$ more likely to have enhanced security compared to households with lowest income, i.e., up to $£ 4,999$ (Figure 2). In 2005/06 they were 58\% more likely to have enhanced security than those earning up to $£ 5,000$ (Figure 3). Enhanced security increased most for the lowest income group (21\%) but not nearly enough to remove the original difference $(80 \%)$ in enhanced security used by those in the highest income group (Figure 4): the disparity in enhanced security availability between least and most affluent households was reduced by about 20\% from 1997 to 2005/06 (compare Figure 3 to 2). 
Income - disparities of burglary risk and security availability over time

The income differentials in basic security are not as straightforward as those for the other two categories discussed above. Basic security is more common in low to middle income households $(£ 5,000-£ 29,999)$ in both years. In $2005 / 06$ the most affluent were roughly $50 \%$ less likely to have basic security compared to households with less than $£ 30,000$ (Figure 3). Indeed the sizeable rises in basic security between 1997 and 2005/06 maintained the small disparity between lowest and middle income households but dropped its relative availability among the richest perhaps due to a ceiling effect (Figure 4). It should be underlined that, with the exception of basic security which is similarly available to all income groups within $£ 5,000-£ 29,999$, house security disparities are proportional to household income. For instance, the richest had $60 \%$ and $46 \%$ more enhanced security but $50 \%$ less inadequate security than the second lowest income group (i.e., £5,000-£9,999) in 1997 and 2005/06, respectively.

\section{Burglary Differentials}

From the mid 1990's burglary rates dropped nationally at an unprecedented rate (58\%, Walker et al. 2009), but were these falls equally experienced across all population segments defined by income? Figure 5, which gives burglary with entry risk trends across income groups from 1995 to 2005/06, shows that they have indeed albeit with varying slopes. The poorest households (up to $£ 4,999$ per annum) were more likely to be successfully burgled than any other income group and with noticeable difference over time. In 2005/06 they were twice as likely as households earning at least $£ 5,000$ per annum. The second most vulnerable in the second half of the decade were households at $£ 5,000-£ 9,999$ while the least burgled for most of the 
Income - disparities of burglary risk and security availability over time

$1995-2005 / 06$ period were middle income households (£20,000-£29,999). The burglary risk of the lower and upper middle income groups (i.e., £10,000-£19,999 and $£ 30,000-£ 49,999)$ and their trends were effectively identical during the entire decade. In 2005/06 burglary risks of all income population segments except the poorest converged. The association between income and burglary risk is statistically significant for all years examined $\left(\chi^{2}=15.51,18.86,28.34,30.18,50.48\right.$ and 30.22 at 6 (5 for the 1996 BCS) degrees of freedom and p-values $\leq 0.000$ (except 0.008 for the 1996 BCS and 0.004 for the1998 BCS), for 1995, 1997, 1999, 2001/02, 2003/04 2005/06 respectively).

$<$ Figure 5 about here $>$

The average drop in burglary with entry across income groups between 1997 and $2005 / 6$ was $58 \%$, the lowest falls being for those in the highest (over $£ 50,000$ ) income group (49\%) and the lowest (under $£ 5,000)$ income group (47\%), the other income groups varying between 54\% (£10,000-£19,999) and roughly 59\% (£20,000 $£ 49,999)$. Figure 6 shows trends indexed to the lowest income group over time. In 1997 the most affluent were $40 \%$ less likely to be (successfully) burgled than the poorest and even less so in 2005/06 (42\%). The differential trend is not linear however and in 1999 the gap in burglary risk between poor and rich narrowed (31\% difference). Non -linear differential trends are observed for all middle income groups compared to the lowest. Burglary risk differences between households at less than $£ 5,000$ and those at $£ 5,000$ - 99,999 , for instance, shrunk temporary in $2001 / 02(16 \%$ difference) but after this year they widened again. Considering any disparities in burglary (with entry) risk between the richest and the second poorest (i.e., $£ 5,000$ $£ 9,999$ ) a widening gap occurred between 1999 and 2003/04. Their corresponding 
Income - disparities of burglary risk and security availability over time

risks were effectively equal in 1997 and between 2003/04 and 2005/06 the gap had closed: the richest were slightly more vulnerable to breaking and entering (by $7.5 \%$ ) than the second lowest income group. The following (and last) results sub-section examines the extent to which security increases contributed to burglary reduction differentials.

$<$ Figures 6 about here $>$

\section{Security, Burglary and Income}

As indicated in the introduction the aim of this study is to investigate the income differentials in the burglary drops that occurred in the last fifteen years or so and test whether these disparities are associated with unequal availability of security devices across population groups. The discussion has so far established that both security availability and, to a less extent if the lowest income group is ignored, burglary risks are unequally distributed across the population and have been so at least since the mid- 1990's. In addition, during the decade of continuous burglary drops to 2005/06 the vulnerability gap between the poorest and all other economic groups, including the richest, widened. That of the second poorest segment did so until 2003/04. During the same decade the enhanced burglary protection gap narrowed only by a fraction and the relative concentration of lack or inadequate protection towards the lower income households (less than $£ 10,000$ ) remained unchanged.

In this section the effects of security on burglary risk are compared within income groups in an effort to explain the widening of income-related differentials in burglary risk between poorest and richest. To ease interpretation the results of three way crosstabulations are standardised against 'no or less than basic security'. Figures 7 and 8 give the relative risk of burglary with entry for households with enhanced and basic 
Income - disparities of burglary risk and security availability over time

security against those without or inadequate security across income groups in 1997 and 2005/06, respectively. As in the previously discussed Figures 2 and 3 the relative risks here can also be presented as odds ratios. For instance, in 1997 households with annual income of $£ 5,000-£ 9,999$ were $77 \%$ less likely to be burgled (with entry) if they had more than basic security than less than basic, including none at all (see Figure 7). Therefore their odds for experiencing this crime type were 0.23 compared to same income households without or inadequate security. In this manner all 12 security - income configurations for each year may be interpreted.

$<$ Figures $7 \& 8$ about here $>$

In 1997 basic and enhanced security afforded significant reductions in successful burglary risks across all income groups except the most affluent (£50,000 or more). An additional exception is that households in the middle income group (£20,000$£ 29,999)$ with basic security were $50 \%$ more at risk than the same income ones without or inadequate security (Figure 7). This result is counter-intuitive and we will not speculate about it. By 2005/06 basic and enhanced security were associated with less than a fifth of burglary risks compared to respective income households without security or with less than basic security except for those at $£ 30,000-£ 49,999$ for which having only basic security confers just below a third of risk (Figure 8). The 2005/06 associations are statistically significant across all income groups $\left(\chi^{2}=63.40,65.12\right.$, $82.12,52.12,93.27$ and 56.16 at 2 degrees of freedom and $p$-values $\leq 0.000$, for respective annual incomes of less than $£ 5,000, £ 5,000-£ 9,999, £ 10,000-£ 19,999$, $£ 20,000-£ 29,999, £ 30,000-£ 49,999$ and $£ 50,000$ or more, respectively). As mentioned, the 1997 ones are significant for all groups except $£ 50,000$ or more with respective $\chi^{2}(p$-value $\leq)=30.85(0.000), 31.09(0.000), 46.20(0.000), 6.01(0.05)$, 
Income - disparities of burglary risk and security availability over time

$17.45(0.000)$, and $0.029(0.99)$ at 2 degrees of freedom for households earning less than $£ 5,000, £ 5,000-£ 9,999, £ 10,000-£ 19,999, £ 20,000-£ 29,999, £ 30,000-£ 49,999$ and $£ 50,000$ or more.

The Security Impact Assessment Tool (SIAT) with the resulting Security Protection Factors (SPF) was introduced in Farrell et al. (2011) to assess the relative protection gained by security devices with respect to car crime for the period 2001-2007. The SPF's are calculated as the relative crime risk of no security against any security device under investigation. Here this technique has been applied with respect to burglary security and also expanded to test whether the afforded protection differs across population sub-groups classified by income overt time. These SIAT results are presented in Figures 9 and 10 for 1997 and 2005/06, respectively, while Figure 11 gives the SPF's over time change for each income group.

$<$ Figures $9-11$ about here $>$

Figure 9 shows, for instance, that in 1997 enhanced security conferred roughly a fourfold burglary protection compared to no security or less than basic security for households earning less than $£ 20,000$ (see the first three bars). In $2005 / 06$, with national burglary with entry risks 58.21\% lower than in 1997 (see Figure 6), enhanced security conferred at least fivefold burglary protection across all population segments. The benefits of enhanced security to the lowest income group were dramatic, as it reduced burglary with entry risks by a factor of roughly 25 . The second most protected (8.52) income group is the second poorest, i.e., households at $£ 5,000$ $£ 9,999$. In both years enhanced security afforded the least (but still considerable in 2005/06) protection to the richest population group. Basic security conferred in 
Income - disparities of burglary risk and security availability over time

general less protection than enhanced for all economic population groups with two exceptions from 2005/06. It conferred a tenfold (9.92 to be precise) and a 6.78

(multiplicative factor) protection to households earning $£ 5,000-£ 9,999$ and $£ 20,000$ $£ 29,999$, respectively.

Enhanced security protection increased predominantly for the poorest (by a multiplicative factor of 5.72) and secondly for the most affluent households (5.04) between 1997 and 2005/06 (see Figure 11). For households earning £5,000-£29,999 the over time SPF changes for basic security were over twice as high as protection conferred by enhanced security ( 4.50 versus 1.45$)$ whereas for those at $£ 30,000$ $£ 49,999$ the protection conferred by either security type improved rather evenly $(2.01$ for enhanced and 2.10 for basic security). The general increase of burglary protection that security provided to households can also be seen in the much lower risks in Figure 8 compared to Figure 7.

As seen in the sub-section of security differentials, in 2005/06 the availability of enhanced security was $60 \%$ higher among the richest households compared to those earning less than $£ 5,000$, down only by a fifth from the $80 \%$ gap observed in 1997 (see Figures 3 and 2, respectively). The relatively higher SPF's efficiencies of enhanced security for the lowest income group combined with the small improvement in its availability for the same group may explain the widening of the disparity in burglary (with entry) risk between the least and the most affluent (see earlier Figure $6)^{5}$. By contrast, while both basic and enhanced security were efficient in thwarting burglaries against households in the second lowest income group in 2005/06 (Figures

\footnotetext{
${ }^{5}$ It should be noted however that this work ignores all other individual and contextual risk factors of burglary (Tseloni 1996).
} 
Income - disparities of burglary risk and security availability over time

9 and 10), the protection conferred by the former increased substantially since 1997

(Figure 11). The relative (compared to the richest) basic security availability for the second lowest income group more than doubled during the period examined (Figure 4) and their gap in enhanced security narrowed from $60 \%$ to $46 \%$ (Figures 2 and 3 ). These observations may explain the reversing of burglary risk differentials between the second poorest and the richest group by $2005 / 06$. They do not however address the initial lack of disparity in 1997 and this is a point we return to in the next and concluding section.

\section{Discussion}

Unprecedented crime drops occurred for the most part of the 1990's and continued into the first decade of the new century, at least up to the year of available BCS data at the time this paper is written. Property crimes 'lead' the way as their (until then upward) trends reversed earlier than those of violence rates. Burglary fell in England and Wales from the mid 1990s for all income population groups but income-related victimisation differentials have widened, notwithstanding many initiatives aimed at the poorer sections of the population (Kodz and Pease 2003; Tilley and Webb 1994). Distributive injustices do not appear to have shrunk significantly. The very poor have, if anything, become worse off relative to the rest. In terms of the rank order of distributive justice preferences posited in Table 1, the trend fits the second best (2) which is less than ideal (1) although still preferable to most other possible trends and to those that preceded the downward trajectory of domestic burglary that began in the mid 1990s. 
Income - disparities of burglary risk and security availability over time

Security of the house is linked to substantial reductions in burglary risk. As security levels have improved rather similarly for all income groups the security availability income-related differentials remain. The protection that enhanced security offers is however highest for those who can least afford it. The income-related variation in protection conferred may explain the widening of income-related differentials in burglary risk between poorest and others. The better off can afford more and better security devices that repel burglars and they are at lower risk because they live beyond the routine activities and awareness spaces of offenders who tend to reside in poorer neighbourhoods. That enhanced security confers the least protection to the most affluent may be due to the fact that they are at low initial risk for the reason just given and/ or their houses are targeted by the most experienced and determined burglars who can outwit security devices. By contrast, the least affluent share the same deprived environments with potential offenders and thus they may be victimised by opportunistic burglars who could have easily been deterred by elaborate security devices. This speculation may explain why enhanced security confers considerable burglary protection to the poorest.

In terms of policy this work suggests that improving the availability of enhanced security in poorer households (i.e., those earning less than $£ 10,000$ per annum) will reduce burglary nationally owing to the relatively higher protection produced, and given that displacement remains insignificant. Is there anything that might be done to improve distributive justice as the crime situation improves, specifically in regard to domestic burglary, in practice? Two possibilities are suggested here. The first is that the state capitalise on research on repeat victimisation. This research finds that security upgrades can reduce the risk of repeat incidents (Forrester et al. 1988, 1990; 
Income - disparities of burglary risk and security availability over time

Chenery et al. 1997). Subsidised security upgrades targeted in this way would reduce risk where it is known to be greatest. Moreover, insofar as the poor are at higher risk of burglary and of repeats (and they are less able than the better-off to pay for their own security enhancements), their enhanced security might feed into improvements in the distributive justice. The second possibility relates to processes of 'responsibilisation' that have been noted by Garland (2001). Those who provide rented accommodation (be they private, semi-public or public) might be required to meet minimum security standards for which they are held accountable. This could reduce the vulnerability of those who are poor and have no material stake in the property they inhabit, but whose (lack of) security features puts them at heightened risk of burglary. Students are a low-income group at high risk of burglary, and so university accreditation of the landlords' security precautions is a means of incentivising security (Barbaret et al. 2004). Again this could help ameliorate that source of inequality in domestic burglary risk that relates to security level differences. Policies that allocated resources and responsibilities in these ways might also disable those discretionary distributive mechanisms that are so well exploited by the betteroff.

The two suggestions made here would not, of course, deal with those sources of continued inequality in burglary risk that relate to the geographical distribution of neighbourhoods within cities with different resident patterns or to the ways in which some of those living in poorer neighbourhoods become disposed to commit burglary. But, no-one seems to know how to deal effectively with these sources of crime risk inequality. Nevertheless we do know something about repeat victimisation, security and crime risk. Maybe modest, but practically possible strategies for improving 
Income - disparities of burglary risk and security availability over time

distributive justice in relation to crime victimisation are worth pursuing, at least in the short term.

Having said the above, however, some counterintuitive results point to new directions for comprehending and examining the causality between security and victimisation. For instance, the lack of burglary risk differentials between the second poorest and the richest households in 1997 despite their significant gap in security (see also end of the earlier subsection on security differentials) is a striking observation. Similarly, middle income $(£ 20,000-£ 29,999)$ households were less at risk of burglary with entry than the richest nearly during the entire decade examined (Figure 5) despite their stable lagging in security over this period (Figures 2 and 3). These arguably suggest that security (or lack thereof) is not an independent burglary causal factor. It is rather a mediating protective factor which is affected by similar household (such as income and tenure) and area characteristics (such as deprivation and population density) as criminal victimisation (Tseloni 2006). Therefore its relation to crime is more entwined with household and contextual variables than that suggested by a simple autonomous causal factor, as indeed this paper assumes. Future research should take into account the theoretically endogenous nature of security and analyse it jointly with burglary as two inter-linked facets of individual and contextual burglary vulnerability.

Finally, Rawls accepts that if the advantages accruing to the better off also bring improvements to the less well-off this provides a distributive-justice warrant for them. In relation to security, this could be the case. Technological improvements in security tend to begin by being expensive and then to become cheaper with mass production. Only the rich adopt them to begin with as only they can afford them. The rich provide 
Income - disparities of burglary risk and security availability over time

the market for and stimulus to the innovations from which the less well-to-do benefit once they become affordable. This is a disconcerting thought on which to end! 
Income - disparities of burglary risk and security availability over time

\section{References}

Barberet, R., B. Fisher, G. Farrell and Taylor, H. (2004), University Student Safety in the East Midlands. Home Office Research Findings 61/04. London: Home Office.

Chenery, S., J. Holt, and Pease, K. (1997), Biting Back II: Reducing Repeat

Victimization in Huddersfield. Crime Detection and Prevention Series Paper 82.

London: Police Research Group, U.K. Home Office.

Cohen, L. and Felson, M. (1979), 'Social Change and Crime Rate Trends: A Routine Activity Approach', American Sociological Review, 44: 588-608.

Farrell, G., Tseloni, A., Mailley, J. and Tilley, N., (2011), 'The crime drop and the security hypothesis' Journal of Research in Crime and Delinquency, 48(2).

Farrell, G., Tseloni, A. and Tilley, N. (2011), The effectiveness of vehicle security devices and their role in the crime drop. Criminology and Criminal Justice, An International Journal, 13(1).

Flatley, J., (Ed.), Moon, D. (Ed.), Roe, S., Hall, P. and Moley, S. (2009), Home security, mobile phone theft and stolen goods: Supplementary Volume 3 to Crime in England and Wales 2007/08 Findings from the 2007/08 British Crime Survey. Home Office Statistical Bulletin 10/09. London: Home Office.

Forrester, D., M. Chatterton and Pease, K. (1988), The Kirkholt Burglary Prevention Project, Rochdale. Crime Prevention Unit Paper 13. London: Crime Prevention Unit, U.K. Home Office.

Forrester, D., S. Frenz, M. O’Connell and Pease, K. (1990), The Kirkholt “Burglary

Prevention Project: Phase II’. Crime Prevention Unit Paper 23. London: Her Majesty's Stationery Office.

Garland, D. (2001), The Culture of Control. Oxford: Oxford University Press. 
Income - disparities of burglary risk and security availability over time

Hales, J., Henderson, L., Collins, D. and Becher, H. (2000), 2000 British Crime Survey (England and Wales): Technical Report. London: National Centre for Social Research.

Hesseling, R. (1994), 'Displacement: A Review of the Empirical Literature', in R.

Clarke (ed) Crime Prevention Studies, Vol 3. Monsey NY: Criminal Justice Press.

Guerette, R. and Bowers, K. (2009), 'Assessing the extent of crime displacement and diffusion of benefits: a review of situational crime prevention initiatives.'

Criminology 47(4): 1331-1368.

Kodz, J. and Pease, K. (2003), Reducing Burglary Initiative: early findings on burglary reduction. Findings 204. London: Home Office.

Maguire, M. (1982), Burglary in a dwelling. London: Heinemann.

Nicholas, S., Povey, D., Walker, A. and Kershaw, C. (2005), Crime in England and

Wales 2004/2005. Home Office Statistical Bulletin 11/05. London: Home Office.

Rawls, J. (1971), A Theory of Justice. Cambridge Mass: Harvard University Press.

Tilley, N. (2009) Crime Prevention. Cullompton, Devon: Willan.

Tilley, N. (Forthcoming), Community, Security and Distributive Justice, in V.

Ceccato (Ed,) Urban Fabric of Crime and Fear. New York: Springer.

Tilley, N. and Webb, J. (1994), Burglary Reduction: Findings from Safer Cities

Schemes. Crime Prevention Unit Paper 51. London: Home Office.

Tseloni, A. (2006), Multilevel modelling of the number of property crimes: Household and area effects. Journal of the Royal Statistical Society Series A-Statistics in Society, 169(2): 205-233.

Tseloni, A., Mailley, J., Farrell, G. and Tilley, N. (2010), The international crime drop: Trends and variations. European Journal of Criminology, 7(5): 375-394. 
Income - disparities of burglary risk and security availability over time

Walker, A., Flatley, J., Kershaw, C. and Moon, D. (2009), Crime in England and Wales 2008/09 Volume 1 Findings from the British Crime Survey and police recorded crime, Home Office Statistical Bulletin 11/09. London: Home Office. 
Income - disparities of burglary risk and security availability over time

Table 1: Crime risk trend preference order

\begin{tabular}{l|llll}
\hline $\begin{array}{l}\text { Rank } \\
\text { preference } \\
\text { order }\end{array}$ & All crime & $\begin{array}{l}\text { Crime risk } \\
\text { amongst } \\
\text { lower risk } \\
\text { group }\end{array}$ & $\begin{array}{l}\text { Crime risk } \\
\text { amongst } \\
\text { higher risk } \\
\text { group }\end{array}$ & $\begin{array}{l}\text { Difference in } \\
\text { crime risk } \\
\text { between } \\
\text { lower and } \\
\text { higher risk } \\
\text { group }\end{array}$ \\
\hline 1 & & & & Decreases \\
2 & Decreases & Decreases & Decreases & Increases \\
3 & Decreases & Decreases & Decreases & Decreases \\
4 & Decreases & Increases & Decreases & Increases \\
5 & Decreases & Decreases & Increases & Decreases \\
6 & Increases & Increases & Decreases & Increases \\
7 & Increases & Decreases & Increases & Inces \\
8 & Increases & Increases & Increases & $\begin{array}{l}\text { Decreases } \\
\text { Increases }\end{array}$ \\
\hline
\end{tabular}

Table 2: Availability of burglary security devices in households, 1998 and 2005/06

British Crime Survey.

\begin{tabular}{lrr}
\hline \multicolumn{1}{c}{ Security Devices } & \multicolumn{2}{c}{ Years } \\
\hline & 1997 & $2005 / 06$ \\
\hline Burglar alarm & $\mathrm{N}(\%)$ & $\mathrm{N}(\%)$ \\
\hline Dummy alarm box & $1,790(24.2)$ & $1,781(29.5)$ \\
\hline Double locks/ Deadlocks & $194(3.5)$ & $225(5.3)$ \\
\hline Security chains/ Door bars & $5,358(72.3)$ & $4,866(80.6)$ \\
\hline Window locks & $4,371(59.0)$ & $2,023(33.5)$ \\
\hline Indoor lights on a timer or sensor switch & $5,266(71.1)$ & $5,171(85.7)$ \\
\hline Outdoor lights on a timer or sensor switch & $1,661(22.4)$ & $1,580(26.2)$ \\
\hline Window bars or grills & $2,742(37.0)$ & $2,694(44.6)$ \\
\hline Bars, metal grills or a bar door & $586(7.9)$ & $134(2.2)$ \\
\cline { 2 - 3 } Dog & $1,664(22.5)$ & $107(1.8)$ \\
\hline Sample base & 7,409 & - \\
\hline
\end{tabular}


Income - disparities of burglary risk and security availability over time

Figure 1: Income distribution in England and Wales, 1998 and 2005/06 British Crime Survey data.

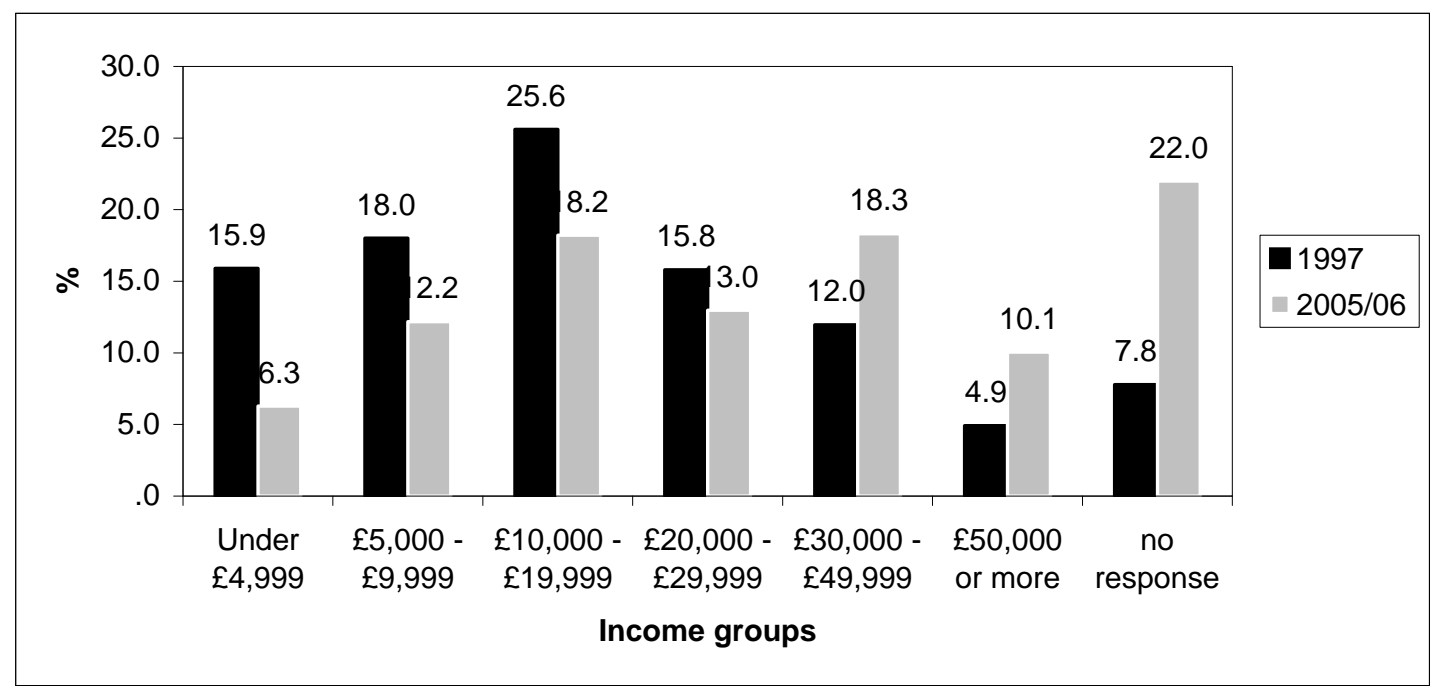


Income - disparities of burglary risk and security availability over time

Figure 2: Security availability indexed to lowest income group 1998 British Crime Survey.

$\left.\begin{array}{|rr}200.0 \\ 180.0 \\ 160.0\end{array}\right]$

Figure 3: Security availability indexed to lowest income group 2005/06 British Crime Survey.

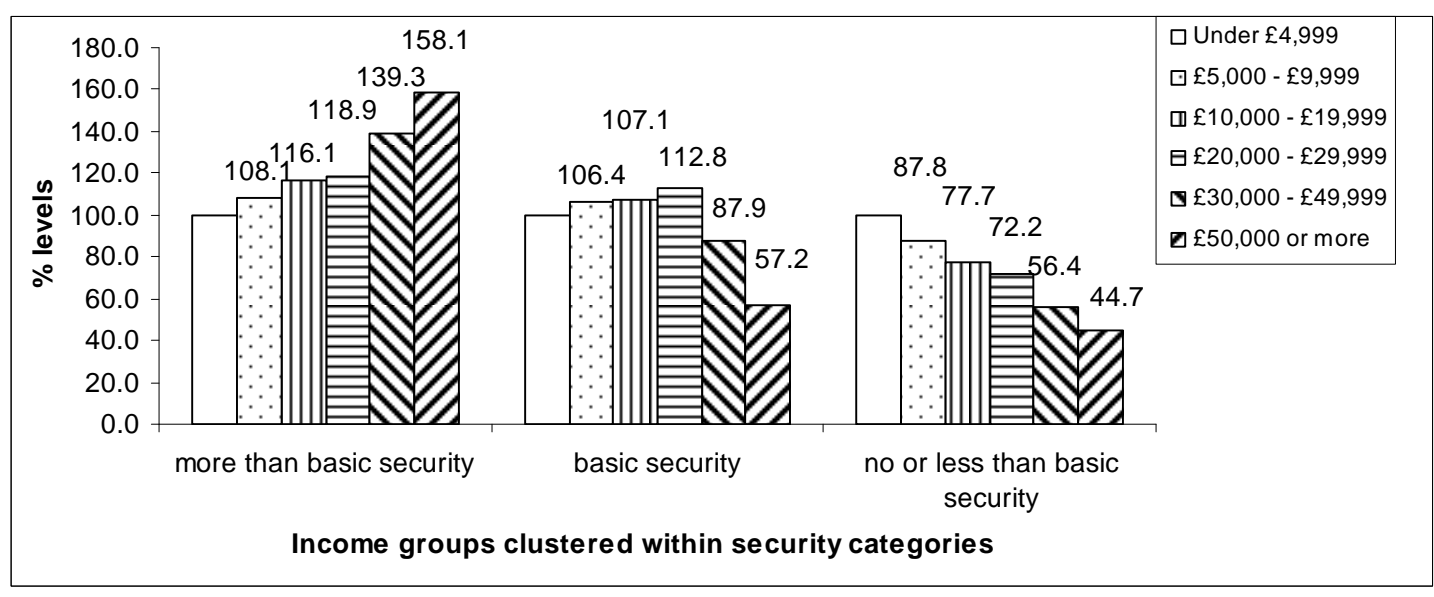


Income - disparities of burglary risk and security availability over time

Figure 4: Percentage change in security across income groups, from 1997 to 2005/06.

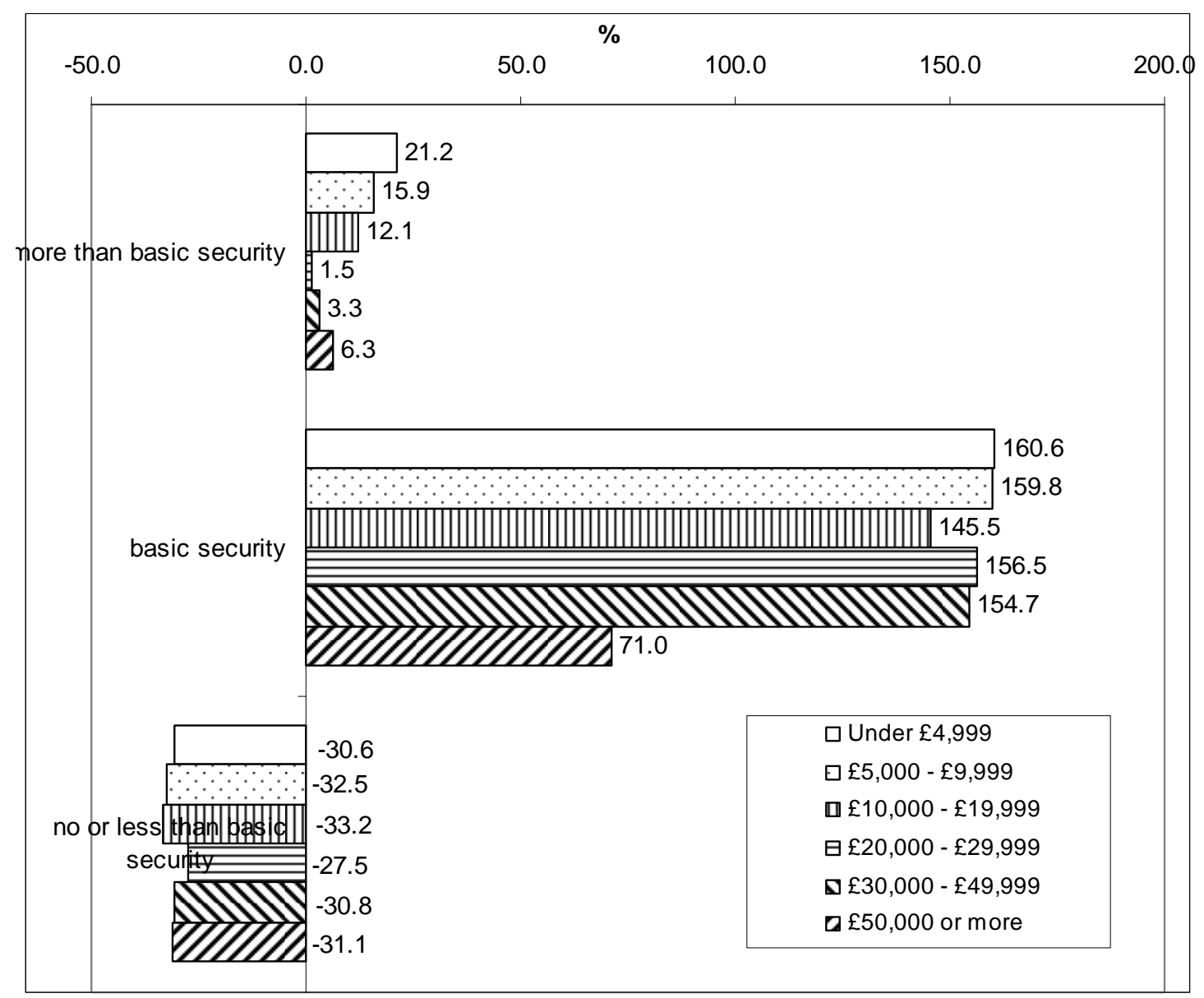


Income - disparities of burglary risk and security availability over time

Figure 5: Burglary with entry (prevalence) trends across income groups from 1995 to 2005/06.

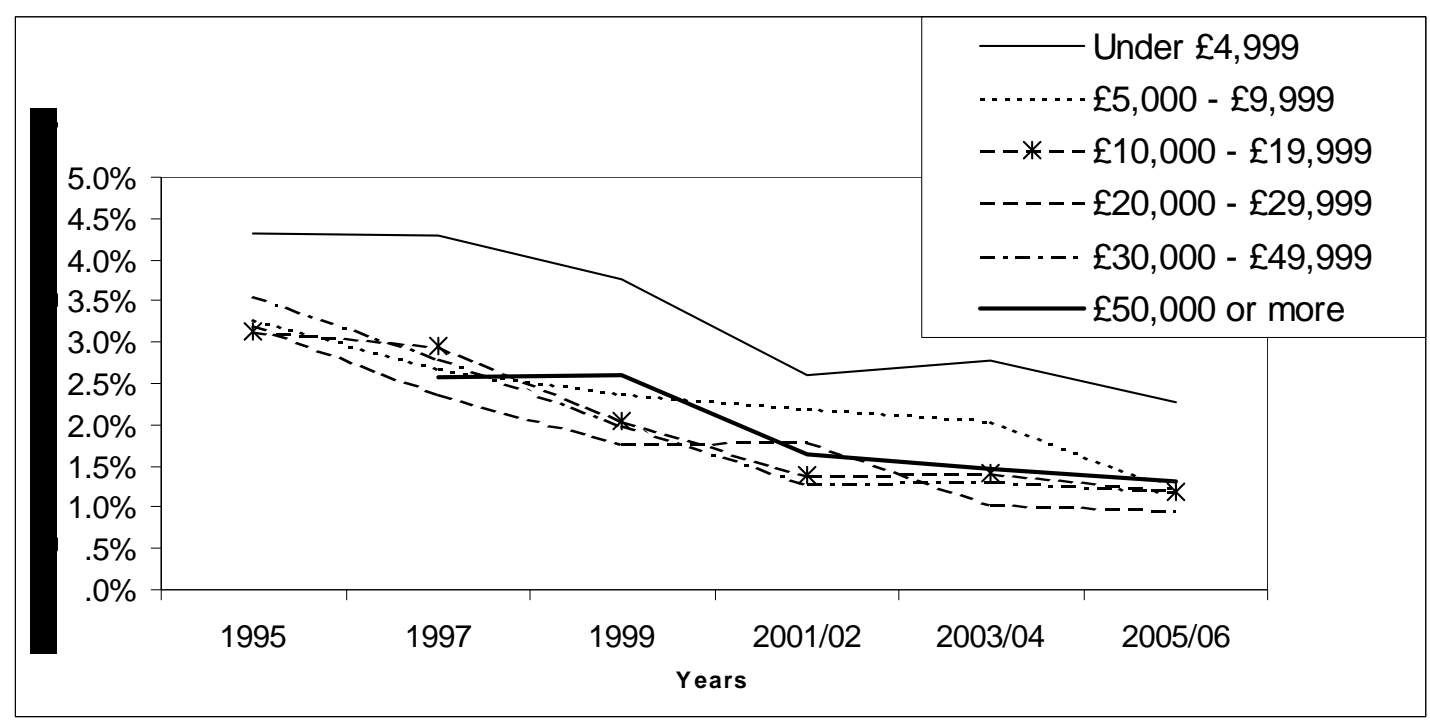


Income - disparities of burglary risk and security availability over time

Figure 6: Burglary with entry (prevalence) trends indexed to lowest income group from 1995 to 2005/06 (burglary with entry risk of lowest income group=100).

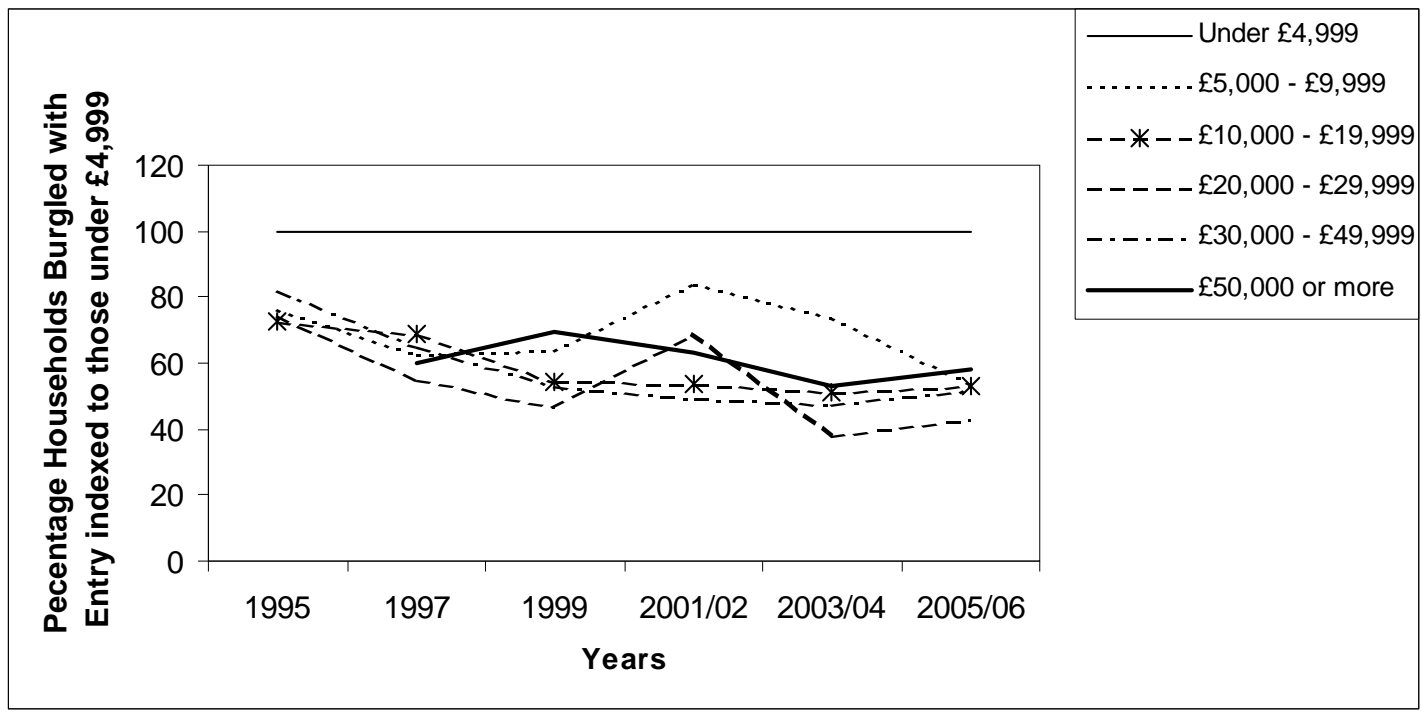


Income - disparities of burglary risk and security availability over time

Figure 7: Risk of burglary with entry over security availability indexed to none or inadequate security across income groups, 1998 British Crime Survey (burglary with entry risk for a household without or inadequate security=100).

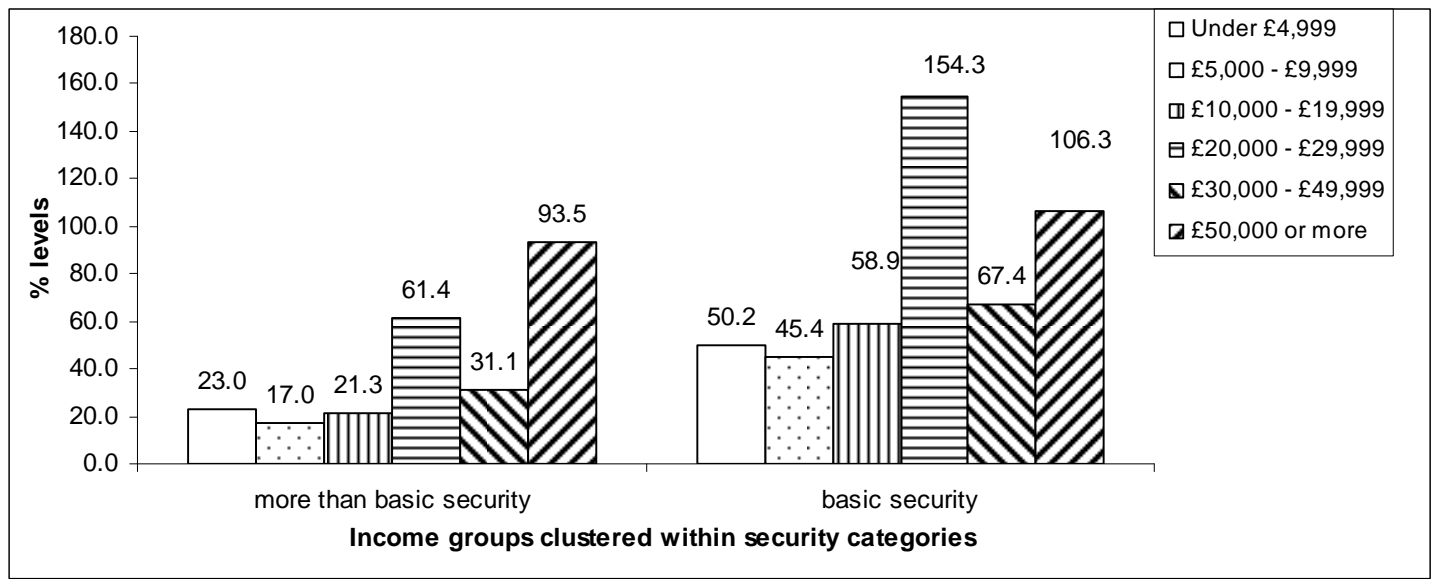

Figure 8: Risk of burglary with entry over security availability indexed to none or inadequate security across income groups, 2005/06 British Crime Survey (burglary with entry risk for a household without or inadequate security $=100$ ).

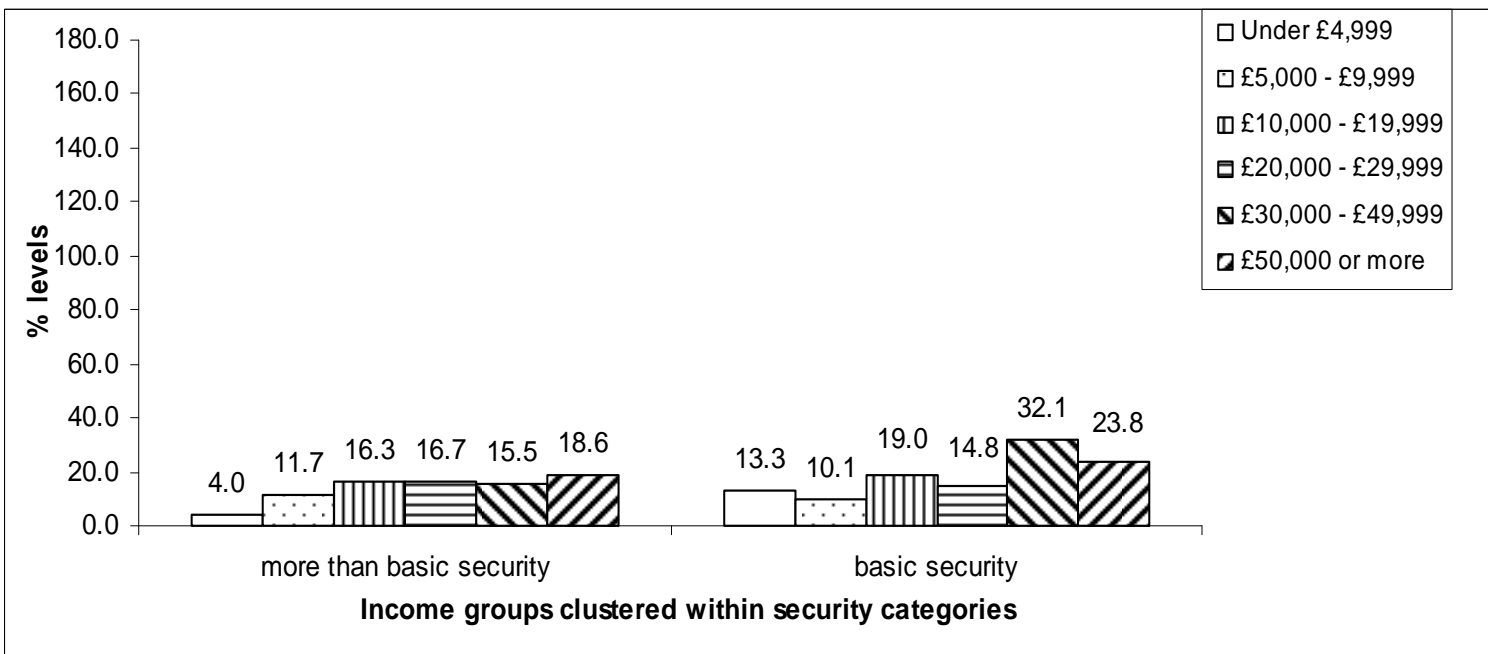


Income - disparities of burglary risk and security availability over time

Figure 9: Security Protection Factors against burglary with entry across income groups, 1998 British Crime Survey.

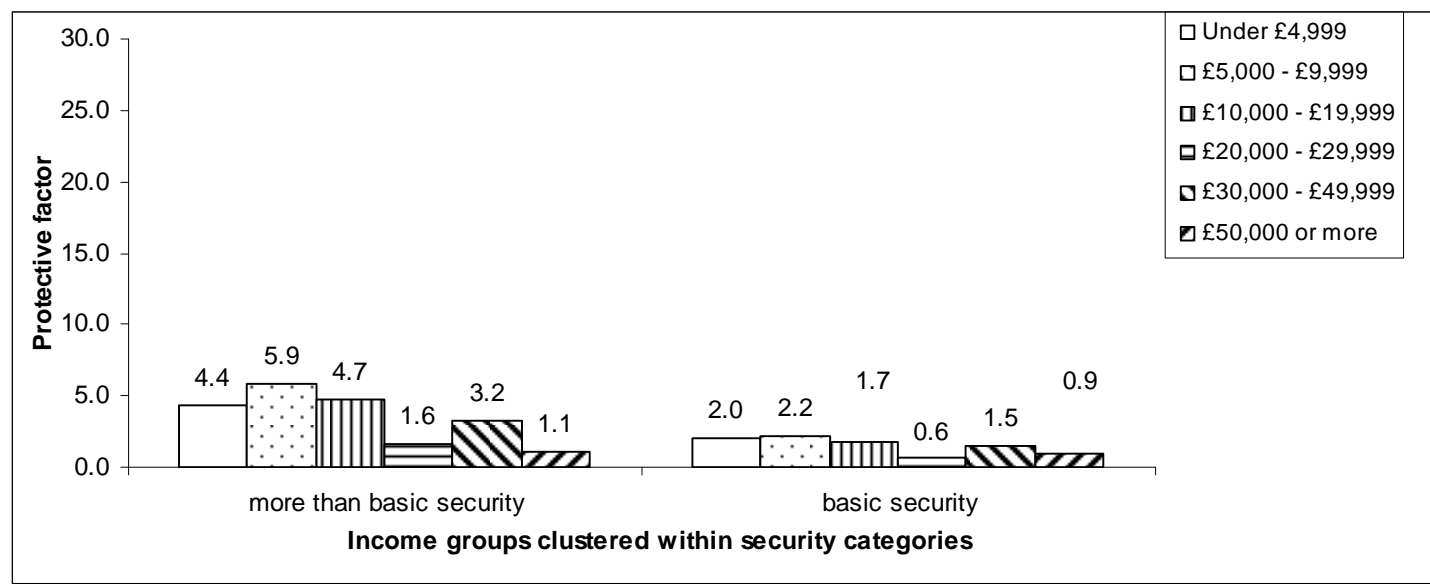

Figure 10: Security Protection Factors against burglary with entry across income groups, 2005/06 British Crime Survey.

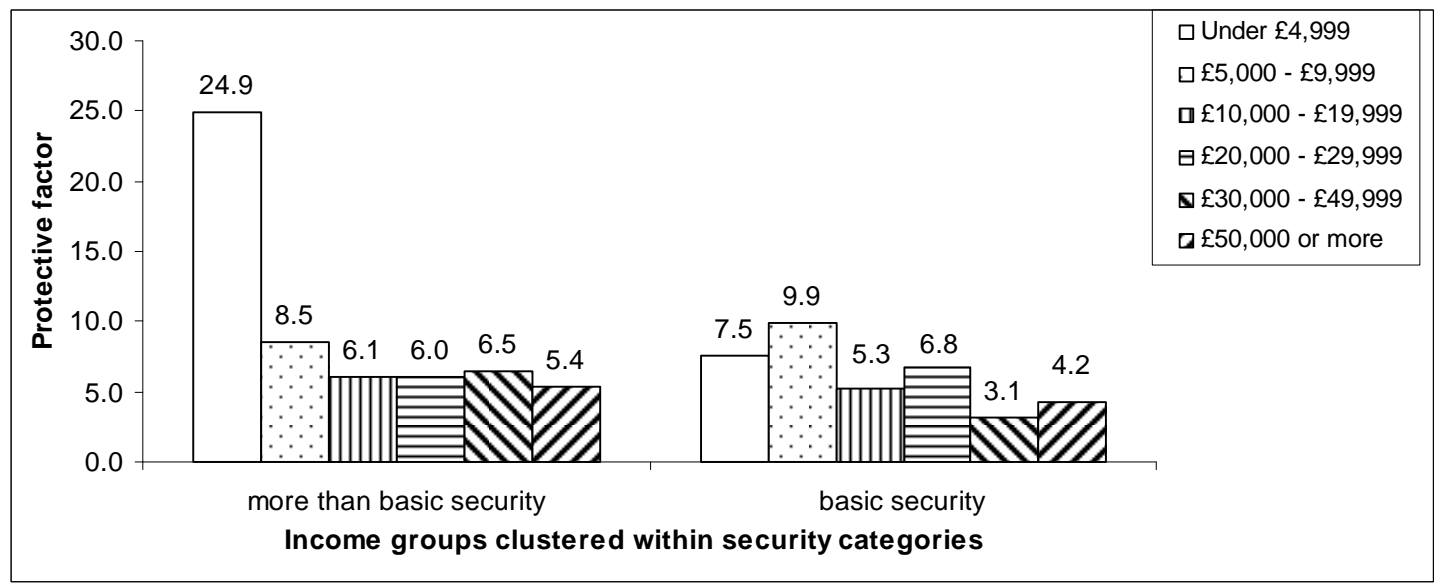


Income - disparities of burglary risk and security availability over time

Figure 11: Multiplicative change of Security Protection Factors against burglary with entry across income groups from 1997 to 2005/06.

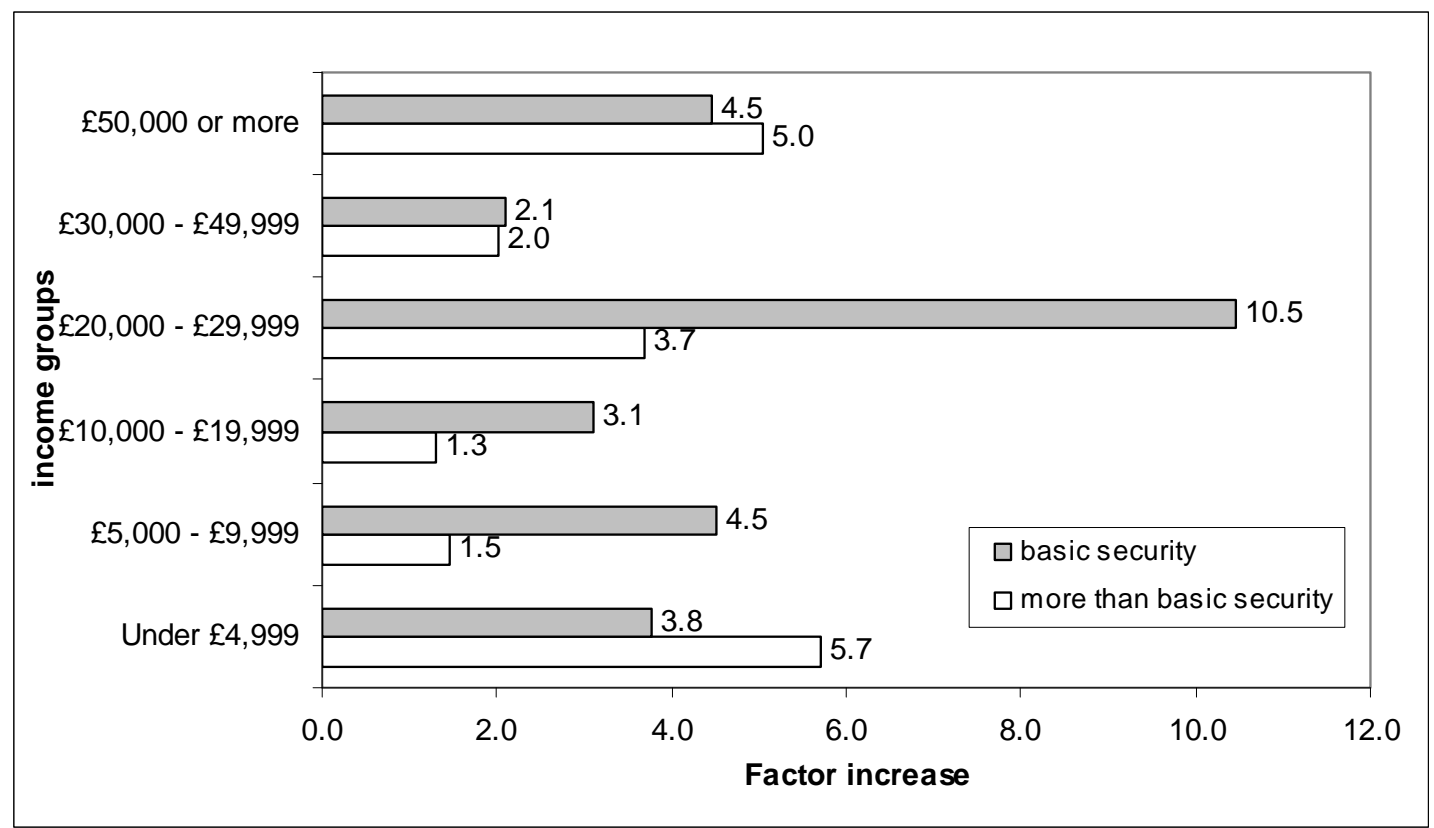

